7. Bouma BN, Marx PF, Mosnier LO, et al. Thrombin-activatable fibrinolysis inhibitor (TAFI, plasma procarboxypeptidase $\mathrm{B}$, procarboxypeptidase $\mathrm{R}$, procarboxypeptidase U). Thromb Res 2001; 101: 329-54. 8. Wang W, Hendriks DF, Scharpe SS. Carboxy-peptidase U, a plasma carboxypeptidase with high affinity for plasminogen. J Biol Chem 1994; 269: 15937-44.
9. Valnickova Z, Thogersen I B, Christensen S, et al. Activated human plasma carboxypeptidase B is retained in the blood by binding to $\alpha_{2}$-macroglobulin and pregnancy zone protein. J Biol Chem 1996; 271: $12937-12943$.
10. Fareed J, Callas DD, Hoppensteadt D, et al. Tissue factor antigen levels in various biological fluids. Blood Coagul Fibrinolysis. 1995; 6 (Suppl. 1): S32-6.

11. Suzuki M, Kudo A, Otawara Y, et al. Extrinsic pathway of blood coagulation and thrombin in the cerebrospinal fluid after subarachnoid hemorrhage. Neurosurgery 1999; 44: 487-93.

\title{
Detection of prothrombin gene polymorphism at position 20209 (PT20209C/T): Pilot study in a black population in the United Kingdom
}

\section{Dear Sir,}

Knowledge of the genetic risk factors underlying venous thrombo-embolism (VTE) in the black population remains sparse (1, $2)$. The two most common genetic variants that predispose to thrombosis (Factor V Leiden and Prothrombin (PT) 20210G/A) occur predominantly in those of European origin and are rare in other ethnic groups (3). Despite this, venous thrombosis has a worldwide prevalence, suggesting that populations of non-European origin possess previously uncharacterised prothrombotic mutations (2). Warshawsky et al have reported a novel C to T mutation occurring one base pair (bp) upstream from the known PT20210G/A polymorphism in four unrelated African-American patients (4). Three of these patients had a history of venous thrombosis or stroke. The polymorphism was absent in 440 individuals from other US ethnic groups including Caucasians, Hispanics, Asians and Native-Americans. The world population distribution and clinical significance of this novel polymorphism remains unclear. As this polymorphism was restricted to African-Americans (most of whom had experienced thromboembolic events), we hypothesised that it might represent a candidate prothrombotic mutation in the UK black population.

We studied a previously reported group of 125 black subjects (5), 61 with a history of deep vein thrombosis (DVT) (27 male and 34 female, mean age 56.2 years, SD 14.6) and 64 healthy controls ( 9 male and 55 female, mean age 55 years, SD 14). All subjects were of African $(28.8 \%)$ or Afro-Caribbean origin (71.2\%) and had negative thrombophilia tests including genotyping for FV Leiden and PT20210A and phenotypic studies for activated protein $\mathrm{C}$ resistance, antithrombin, protein $\mathrm{C}$, free protein $\mathrm{S}$ and lupus anticoagulant. Subjects with hereditary thrombophilia $(9.1 \%)$ were excluded from the study. The control subjects had no known history of VTE or malignancy. Cases had completed a standard course of anticoagulant treatment for objectively confirmed DVT at least 3 months previously. A panel of

\footnotetext{
Correspondence to:

Dr Roopen Arya

Department of Haematological Medicine

King's College Hospital

Denmark Hill, London. SE59RS, UK

Tel. + 442073463570 , Fax: + 44207346 I5 I2

E-mail: roopen.arya@kcl.ac.uk
}

Received September 2, 2004

Accepted after revision October 28, 2004

Thromb Haemost 2005; 93: I79-80
50 healthy Asian Indians and 69 healthy South East Asians were also screened for the presence of this polymorphism. A PCRRFLP based assay that incorporated an invariant digestion site was developed for detection of the PT20209C/T polymorphism (Fig. 1A).

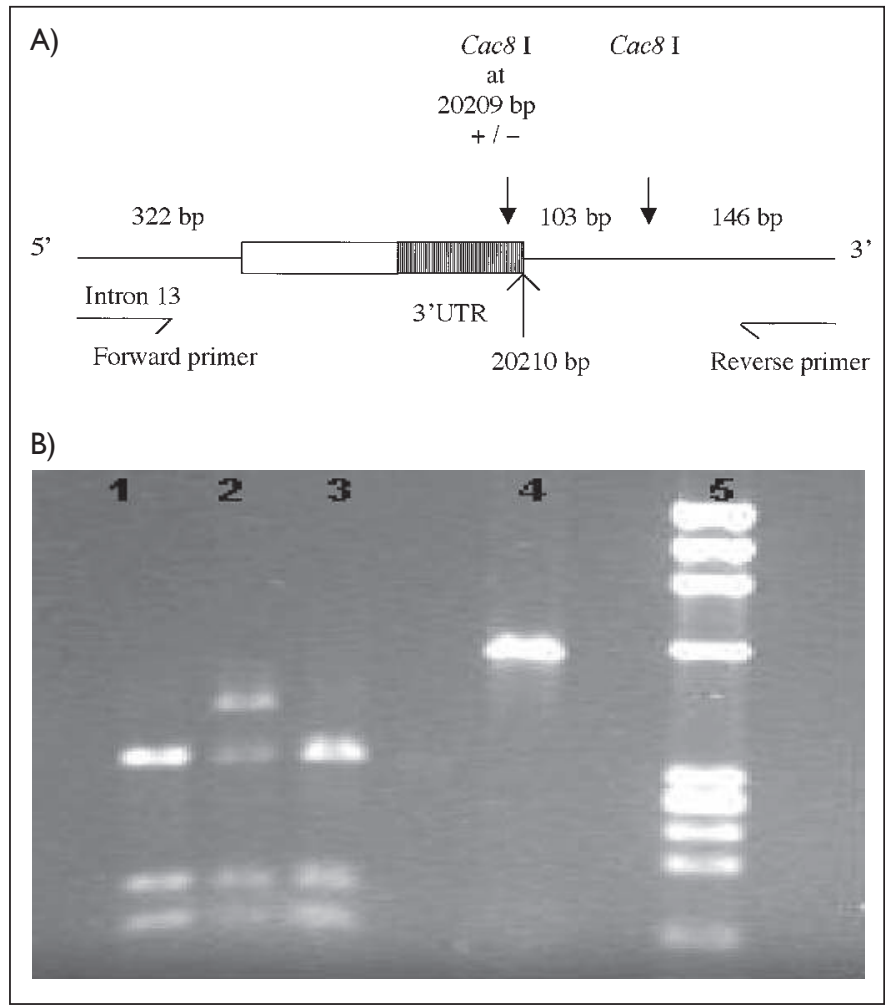

Figure I: PCR-RFLP based assay for detection of the PT20209C/T polymorphism. A: The terminal exon (exon 14) including the 3' untranslated region (3'UTR) (hatch box) of the prothrombin gene is amplified by PCR. Presence of the T variant at position 20209 of the prothrombin gene removes a cutting site for Cac8 I. An invariant Cac8 I cutting site acts as a control for complete digestion of the PCR product. Hence, Cac8 I restriction analysis of wild type will produce 3 fragments of $322 \mathrm{bp}, 103 \mathrm{bp}$ and $146 \mathrm{bp}$; homozygotes for prothrombin C20209T will produce 425 bp and I 46 bp while C20209T heterozygotes will produce 4 DNA fragments of 425 bp, 322 bp, I 03 bp and I 46 bp. B. Agarose gel electrophoresis of PCR products after an overnight digestion with $\mathrm{Cac} 8 \mathrm{I}$ at $37^{\circ} \mathrm{C}$. Lanes I and 3 represent wild type prothrombin gene; lane 2 heterozygote for prothrombin C20209T; lane 4 uncut PCR product and lane 5 DNA molecular marker $\phi$ XI74-Hae III. 
Of the 61 black patients, one $\mathrm{C} / \mathrm{T}$ heterozygote was found (Fig. 1B) whereas all the 64 black controls were of the wild type. A DNA sequence analysis was subsequently performed and confirmed heterozygosity for the $\mathrm{C} / \mathrm{T}$ polymorphism, $1 \mathrm{bp}$ upstream from the known 20210G/A mutation at position 20209. A review of the medical history of this patient revealed that he was a 79 year-old Jamaican male with prostatic carcinoma and proximal DVT. The C20209T polymorphism was not found in any of the 50 healthy Asian Indians or 69 healthy South East Asians tested.

PT20209C/T is a novel polymorphism previously reported in 4 unrelated African Americans but not in white Americans (4). We have demonstrated a low prevalence $(1.6 \%)$ of this polymorphism in 61 black subjects with venous thrombosis and an absence of the polymorphism in healthy black controls, Asian Indians and SE Asians. The true prevalence of the PT20209C/T polymorphism cannot be defined in a small case-control study but it would appear to be lower in our study population (heterozygosity $0.8 \%$ ) compared to African-Americans (heterozygosity $4.9 \%$ ). Interestingly, in an unpublished study of 503 indi- viduals in the UK (unknown ethnicity) referred for standard thrombophilia tests, only one $\mathrm{C} / \mathrm{T}$ heterozygote was detected. Thus, it would appear that the frequency of this mutation in the UK population is not high. The clinical significance of the 20209C/T polymorphism among the black population remains unclear and there are as yet insufficient data to suggest a possible prothrombotic role. Whether the PT20209C/T polymorphism is associated with elevated prothrombin levels is unknown but this may be a possibility given its proximity to PT20210G/A. Further research is required to clarify the prevalence and significance of the PT20209C/T in the black population.

Peng Yen Soo', Raj K. Patel', Steve Best', Roopen Arya², Swee Lay Thein ${ }^{1,2}$

'Department of Haematological Medicine, Guy's, King's and St Thomas' School of Medicine, King's College London, London, UK 2Department of Haematological Medicine, King's College Hospital, London, UK

\section{References}

1. Dowling NF, Austin H, Dilley A, et al. The epidemiology of venous thromboembolism in Caucasians and African-Americans: the GATE Study. J Thromb Haemost 2003; 1: 80-7.
2. Patel RK, Ford E, Thumpston J, et al. Risk factors for venous thrombosis in the black population. Thromb Haemost 2003; 90: 835-8.

3. Rees DC, Chapman NH, Webster MT, et al. Born to clot: the European burden. Br J Haematol 1999; 105: 564-6.
4. Warshawsky I, Hren C, Sercia L, et al. Detection of a Novel Point Mutation of the prothrombin gene at position 20209. Diagn Mol Pathol 2002; 11: 152-6.

5. Patel RK, Ford E, Thumpston J, et al. Coagulation factor levels and venous thrombosis in the black population. Thromb Haemost 2004; 91: 828-30.

\section{A functional serotonin transporter (SLC6A4) polymorphism modifies the association of smoking and diabetes with asymptomatic carotid atherosclerosis}

\section{Dear Sir,}

Serotonin (5-HT), a crucial mediator of platelet activation, is conveyed into the cells through a membrane transporter. There is a 44-bp insertion/deletion polymorphism (long [L] and short [S] allele) in the promoter region of the SLC6A4 gene, coding for the 5-HT transporter. The $\mathrm{L}$ allele is associated with higher promoter activity (1), increased 5-HT uptake in platelets (2) and

\footnotetext{
*Both authors contributed equally.
}

\section{Correspondence to:}

Birger Wolff, MD

Klinik für Innere Medizin B

Ernst-Moritz-Arndt-Universität Greifswald

Friedrich-Loeffler-Straße 23 a

17487 Greifswald, Germany

Tel.: +49-3834-866656, Fax: +49-3834-866657

E-mail: bwolff@pop.uni-greifswald.de

Received April 26, 2004

Accepted after resubmission October 28, 2004

Financial support:

This work was supported by the German Federal Ministry of Education, Science, Research, and Technology (grant 0 I GG 9845/5, 0IZZ96030) and from the Ministry for

Education, Research and Cultural Affairs and the Ministry for Social Affairs of the State Mecklenburg-Western Pomerania.

Thromb Haemost 2005; 93: I 80-2 with higher 5-HT plasma levels (3). Recently, three case-control studies described an association of the SLC6A4 polymorphism with coronary heart disease (CHD) and myocardial infarction (4-6). Carotid atherosclerosis (CA) measured by ultrasound correlates with existing CHD and is predictive of cardiac events in individuals without clinically evident disease (7). We consequently investigated the association of the SLC6A4 polymorphism with asymptomatic CA among participants of the Study of Health in Pomerania (SHIP).

For this purpose, a total of 629 subjects aged 45 to 79 years had completed genotyping by PCR and ultrasound investigation of the carotid arteries as previously described (8). CA was defined as presence of atherosclerotic plaques in the extracranial carotids on either side (common, internal, external carotids and carotid bifurcation). Hypertension was defined as a systolic blood pressure (BP) of $\geq 160 \mathrm{mmHg}$, a diastolic BP of $\geq 95$ $\mathrm{mmHg}$, or intake of antihypertensives. Smoking was defined as current smoking of at least one cigarette per day (mean daily consumption: $13.4 \pm 8.8$ cigarettes), diabetes as self-reported physician diagnosis of diabetes, or serum haemoglobin $\mathrm{A}_{1 \mathrm{C}}\left(\mathrm{HbA}_{1 \mathrm{C}}\right)$ of $>7.0 \%$. Non-fasting blood samples were taken and lipids and $\mathrm{HbA}_{1 \mathrm{C}}$ were determined according to standard procedures. Data were analyzed using ANOVA and logistic regression. Gene-to- 